\title{
Uptake of a national primary mental health program by young people in Australia
}

\author{
Bridget Bassilios ${ }^{*}$, Angela Nicholas, Lennart Reifels and Jane Pirkis
}

\begin{abstract}
Background: The purpose of this study was to examine the uptake of an Australian primary mental health care program (Access to Allied Psychological Services) by young people aged 12 to 25 years and the characteristics of consumers and the treatments received. Data were sourced from a national web-based minimum dataset.

Results: Between 1 July 2003 and 30 June 2012, 51716 young consumers received 245704 sessions via the primary mental health program. Around two thirds were female and the average age was 19 years. The majority had depressive and/or anxiety disorders.

Most services were delivered to individuals (including just the young person and/or the young person with one or both parents), in a face-to-face context and free of charge. Cognitive and behavioral strategies were the most common interventions delivered.

Conclusions: The primary mental health care program has been well utilized by people aged 12 to 25 years. Similar programs in other developed countries may improve access to primary mental health care for young people.
\end{abstract}

Keywords: Young people, Youth, Adolescents, Mental health services, Primary health care, Mental health policy

\section{Background}

Youth mental health is an important public health problem in Australia and internationally. Approximately one in four young people have mental health problems but tend not to access services [1]. Primary mental health services have an important role to play in recognizing vulnerable individuals and offering appropriate treatment.

The Australian Government-funded Access to Allied Psychological Services (ATAPS) program is an example of a primary mental health care program that may improve access to mental health services for young people. Operating since 2001, ATAPS enables predominantly general practitioners (GPs; the Australian term for family physicians) to refer patients with high prevalence disorders (e.g., depression and anxiety) to mental health professionals (predominantly psychologists) for free or low-cost, evidence-based mental health care (most commonly cognitive behavioral therapy, or CBT). This care is delivered in up to 12 (or 18 in exceptional circumstances) individual and/or up to 12 group sessions. Review by the referring

\footnotetext{
* Correspondence: b.bassilios@unimelb.edu.au

Centre for Mental Health, Melbourne School of Population and Global Health, University of Melbourne, Victoria 3010, Australia
}

GP is essential after each block of six sessions and/or the final session [2]. Nation-wide, ATAPS is currently implemented by 61 Medicare Locals, which are regionally based organizations that coordinate primary health care delivery whilst striving to address local health care needs and service gaps.

The introduction of the Better Access to Psychiatrists, Psychologists and General Practitioners (Better Access) initiative in 2006 has influenced the nature and direction of ATAPS. Better Access facilitates similar access to primary mental health care via fee-for-service rebates under Medicare, Australia's publicly funded universal health care system, operated by the government authority Medicare Australia [3]; however, unlike ATAPS its funding is uncapped. Consequently, ATAPS has since offered more flexible services to particular at-risk populations (e.g., people at risk of suicide, people affected by extreme climatic events, children with mental disorders) that are not available via either the original form of ATAPS, which operates simultaneously, or via Better Access.

ATAPS has been independently evaluated since its introduction, with findings indicating high program uptake in both urban and rural areas $[4,5]$ and positive 
outcomes for consumers [6] and providers [7]. To date, however, the ATAPS evaluation has not specifically explored ATAPS' performance in terms of providing care for young people as a particular at-risk population. The current paper, therefore, aims to describe the uptake of ATAPS by young people aged 12 to 25 years, the characteristics of this group of consumers and the interventions delivered to them. This age range was selected in order to be more inclusive given the variations in the definitions 'young people' by different services and researchers internationally, and to facilitate comparisons with other Australian youth mental health services, such as headspace National Youth Mental Health Foundation [8], which targets 12 to 25 year olds.

\section{Method}

The ongoing evaluation of ATAPS has received approval from The University of Melbourne's Human Research Ethics Committee.

\section{Data source}

\section{Minimum dataset}

As per contractual requirements with the Australian Department of Health, data were collected by ATAPS service providers and entered by project officers (or providers) into a web-based purpose-designed national minimum dataset. The data includes the numbers of professionals and consumers involved in the program; socio-demographic (e.g., age, gender, level of income) and clinical (e.g., diagnosis, previous psychiatric service use) characteristics of consumers; the number, type and duration of sessions and the nature of the interventions provided. Data were downloaded from the minimum dataset on 29 October 2012.

\section{Data analyses}

Consumers were included in the analyses if they were aged between 12 and 25 years at the time of referral. Descriptive analyses of the uptake of ATAPS, and consumer and session profiles were conducted using SPSS v21. The analysis period was 1 July 2003 to 30 June 2012 .

\section{Results}

\section{Uptake of ATAPS by young people}

Between 1 July 2003 and 30 June 2012, a total of 66264 referrals aged 12 to 25 years were made to ATAPS by 15 045 referrers (99\% GPs), and sessions were conducted by 4461 mental health professionals. This represents approximately $22 \%$ and $20 \%$ of all ATAPS referrals and sessions, respectively, during the analysis period. Overall, 245704 sessions were reported in association with 51 716 (or $78 \%$ of the 66264 referred) consumers who took up the service, making 4.8 the average number of sessions per referral.

Figure 1 shows the number of referrals (resulting in sessions) and the number of sessions delivered by quarter from July 2003 to June 2012. The number of referrals resulting in sessions and the number of sessions gradually increased and peaked in the third quarter of 2006 (1 681 and 7 699, respectively), after which there was a noticeable decline then a one-year period of stability before an overall ongoing pattern of increase. The noted decline is probably attributable to the introduction of the Better Access program in November 2006.

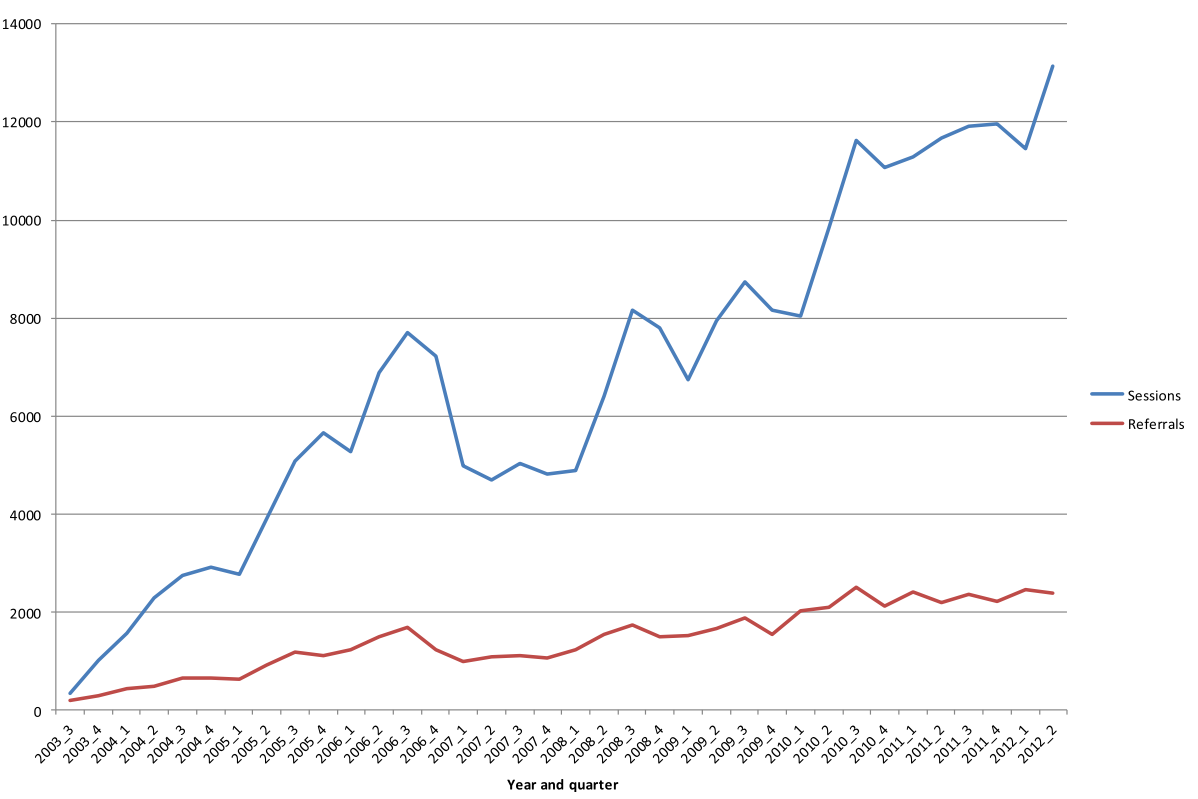

Figure 1 Referrals and sessions of care for young people over the life of ATAPS by quarter, July 2003 to June 2012. 


\section{Socio-demographic and clinical profile of consumers}

Table 1 shows the socio-demographic and clinical characteristics of the 51716 young people referred to ATAPS who received sessions. Over two-thirds of consumers were female, with an average age of 19 years. Approximately two-thirds of the young people (or their families) were receiving a low income, as determined by their GPs. Only one-third of consumers had previously accessed mental health care. Four percent of young consumers were reported to be of Aboriginal, and less than 1\% of Torres Strait Islander, origin. The majority of consumers were diagnosed with depression (55\%) and/or anxiety disorders (43\%). 'Other' free text diagnoses were reported for $19 \%$ of consumers.

\section{Characteristics of sessions}

The profile of sessions delivered to young consumers is shown in Table 2. Almost all sessions (92\%) were delivered to individuals (including just the young person and/ or the young person with one or both parents) in a face to face context (93\%). Sessions of 46 to 60 minutes duration accounted for the vast majority (78\%) of services delivered. The most frequently delivered interventions were CBT-cognitive (45\%) and CBT-behavioral (35\%); however, psycho-education (26\%) and interpersonal therapy $(21 \%)$ were also commonly delivered. Of the 179 852 sessions where payment information was available, the majority (142 840, 80\%) were delivered free of charge. Around 9\% of sessions were not attended.

\section{Discussion}

Substantially, 51716 people aged 12 to 25 years received mental health care through ATAPS during the nine year analysis period. By comparison, and in the context that ATAPS funding is capped while Better Access funding is not, around 194901 people aged 15-24 years received psychological therapy and focused psychological strategies in 2007-2009 via the Better Access program [9]. A further 14548 consumers aged 12 to 25 years were referred to ATAPS but did not take up the service (22\% of all referrals), which is similar to the non-uptake rate for the entire ATAPS program, at 21\% [10], but lower than that (27\%) reported elsewhere [11]. Previous findings have demonstrated that the likelihood of using services increases with symptom severity; [12] therefore it is possible that people referred to ATAPS but who do not take up the service have less severe symptoms. Other possible reasons for not taking up the service which could be further examined are lack of motivation or readiness to change; stigma associated with seeking mental health care; miscommunication with the GP; or access issues, such as the location or cost of the service.

The estimated Australian resident population aged 12 to 25 years in June 2012 was 4081058 [13], one quarter
Table 1 Characteristics of young consumers who received care through ATAPS, July 2003 to June 2012 ( $N=51$ 716)

\begin{tabular}{lrr}
\hline & Frequency & Percent \\
\hline Gender & & \\
Female & 35590 & 68.8 \\
Male & 15281 & 29.5 \\
Missing & 845 & 1.6 \\
Age (years) & & \\
$12-14$ & 5929 & 11.5 \\
$15-17$ & 10819 & 20.9 \\
$18-21$ & 17411 & 33.7 \\
$22-25$ & 17557 & 33.9
\end{tabular}

Low income

Yes

$33498 \quad 64.8$

No

7333

14.2

Unknown

15.1

Missing

Previous psychiatric care

Yes

33.2

No

17145

44.4

Unknown

22970

14.6

Missing

7543

7.8

Aboriginal

Yes

2055

4.0

No

40635

78.1

Unknown

5417

10.5

Missing

3879

7.5

Torres Strait Islander $^{\mathrm{a}}$

Yes

$224 \quad 0.4$

No

41245

79.8

Unknown

5693

11.0

Missing

4554

Diagnosis $^{\mathbf{b}}$

Alcohol and drug use disorders

Psychotic disorders

4.8

Depression

818

Anxiety disorders

28301

Unexplained somatic disorders

22128

Other

870

No formal diagnosis

9912

19.2

Unknown

50

0.1

Missing

1103

2.1

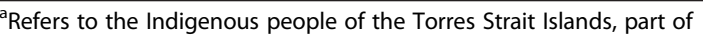
Queensland, Australia, as distinct from other Aboriginal peoples of Australia. ${ }^{\mathrm{b}}$ Multiple responses permitted. 
Table 2 Summary characteristics of sessions provided to young consumers of ATAPS, July 2003 to June 2012 ( $N=245$ 704)

\begin{tabular}{|c|c|c|}
\hline & Frequency & Percent \\
\hline \multicolumn{3}{|l|}{ Duration } \\
\hline $0-30$ mins & 7276 & 3.0 \\
\hline $31-45$ mins & 6160 & 2.5 \\
\hline $46-60$ mins & 192452 & 78.3 \\
\hline Over 60 mins & 22745 & 9.3 \\
\hline Missing & 17071 & 6.9 \\
\hline \multicolumn{3}{|l|}{ Type } \\
\hline Individual & 222592 & 90.6 \\
\hline Child & 3066 & 1.2 \\
\hline Parent(s) & 94 & 0.0 \\
\hline Child \& parent(s) & 662 & 0.3 \\
\hline Group & 5620 & 2.3 \\
\hline Child in group & 111 & 0.0 \\
\hline Parents in group & 3 & 0.0 \\
\hline Missing & 13556 & 5.5 \\
\hline \multicolumn{3}{|l|}{ Modality } \\
\hline Face to face & 228279 & 92.9 \\
\hline Telephone & 1678 & 0.0 \\
\hline Videoconference & 131 & 0.1 \\
\hline Web-based & 55 & 0.0 \\
\hline Missing & 15561 & 6.3 \\
\hline \multicolumn{3}{|l|}{ Consumer fee } \\
\hline Yes & 37012 & 15.1 \\
\hline No & 142840 & 58.1 \\
\hline Missing & 65852 & 26.8 \\
\hline \multicolumn{3}{|l|}{ Interventions $^{a}$} \\
\hline Diagnostic assessment & 41834 & 17.0 \\
\hline Psycho-education & 62893 & 25.6 \\
\hline CBT Behavioural interventions & 85247 & 34.7 \\
\hline CBT Cognitive interventions & 110038 & 44.8 \\
\hline CBT Relaxation strategies & 41468 & 16.9 \\
\hline CBT Skills training & 45706 & 18.6 \\
\hline Interpersonal therapy & 52235 & 21.3 \\
\hline Narrative therapy & 1949 & 0.8 \\
\hline Family therapy & 172 & 0.1 \\
\hline Parent training in behaviour management & 77 & 0.0 \\
\hline Play therapy & 82 & 0.0 \\
\hline Other & 12625 & 5.1 \\
\hline Missing & 41754 & 17.0 \\
\hline
\end{tabular}

${ }^{\mathrm{a}}$ Multiple responses permitted.

of whom had a potential need for mental health services [1]; given that 9391 consumers in this age group accessed ATAPS in the 2011-2012 financial year, this equates to around $1 \%$ of consumers aged 12 to 25 years in potential need of mental health services accessing ATAPS. This rate needs to be interpreted in the context that ATAPS funding is capped and ATAPS is part of a suite of mental health services available for young people, such as Better Access, headspace, Orygen Youth Health and Child and Adolescent Mental Health Services. From 1 July 2003 to 30 June 2012, sessions delivered to people aged 12 to 25 years accounted for $20 \%$ of all ATAPS services. Given that people aged 12 to 25 years comprise around $18 \%$ of the Australian population [13], and that the prevalence of mental disorders is higher in younger age groups, the relative access to ATAPS by young consumers seems reasonable.

The fact that more females have taken up primary health care services via the ATAPS program is not surprising in the context that females with mental disorders in any group are more likely to use services than males [12]. This in turn may be attributable to multiple factors such as lower levels of stoicism and personal stigma associated with mental health problems in females compared with males [14], masculine norms being negatively associated with men's willingness to seek professional help [15], and the advanced mental health literacy of young female Australians [16].

Most consumers were receiving low incomes or were from low income families and had not previously accessed psychiatric services, suggesting that the ATAPS program is addressing access barriers amongst those in need. Given that Indigenous people comprise $2.5 \%$ of the Australian population [17], the finding that around $4 \%$ of consumers were of Aboriginal, and less than $1 \%$ of Torres Strait Islander, origin indicates that they are appropriately accessing ATAPS. However, in the context that Indigenous people have a higher prevalence of mental disorders [18], their access to ATAPS could be improved. Indeed in July 2010, an ATAPS sub-program targeting Indigenous people was introduced that aims to address this inequity.

Findings based on the minimum dataset are limited by lack of corroboration of data such as diagnosis or intervention and may contain unidentified errors. For example, the 'no show' field was not mandatory until June 2013 and has a high rate of missing data, and so it is likely that this figure is currently underestimated and will increase in the future. However, there are several ways in which the quality of data in the minimum dataset is optimized including restriction of data entry options, mandatory data items, validation of data via code to ensure type of data entered matches type of data required and validation against data self-reported by Medicare Locals to the Department of Health, technical features to enable monitoring of each Medicare Local's data patterns, data analysis checks, introduction of statistical 
linkage keys [19] to minimize duplicate patient entry, and provision of a helpdesk and website to support data entry.

Our findings are policy-relevant for both Australia and other developed countries with a similar primary mental health care system that are considering advancing that system. Our study corroborates previous findings suggesting that depressive and anxiety disorders are the most common mental disorders in young people [20]. The ATAPS model, which is predominantly reliant on a GP referral, is appropriate on the grounds that of the $35 \%$ of Australians with mental health problems who seek help, the majority do so from GPs [21]. Although the ATAPS program may not suit all young consumers given that access to services is reliant on their having a GP, ATAPS is a good example of a primary mental health care program which has been delivering services to a substantial number of young people with clinically diagnosable disorders and that facilitates access to free or low-cost treatment. Future evaluation efforts could examine spatial data to determine area-based equity in access to ATAPS by young people.

\section{Abbreviation}

ATAPS: Access to Allied Psychological Services.

\section{Competing interests}

During the study period, the evaluation of ATAPS was funded by the Australian Government's Department of Health.

\section{Authors' contributions}

BB was the lead researcher for the study. She conducted the data analysis and interpretation and drafted the manuscript. AN and LR assisted with data interpretation and drafting the manuscript. JP oversaw the project and assisted with drafting the manuscript. All authors read and approved the final manuscript.

\section{Acknowledgements}

Kylie King and Justine Fletcher (Research Fellows at the Melbourne School of Population and Global Health, University of Melbourne), Grant Blashki (Associate Professor at the Nossal Institute for Global Health, University of Melbourne) and Phillip Burgess (Professor at the School of Population Health, Queensland Centre for Mental Health Research, University of Queensland) have made significant contributions to the broader ATAPS evaluation. The evaluation of ATAPS is funded by the Australian Government's Department of Health.

Received: 13 November 2013 Accepted: 17 March 2014 Published: 21 March 2014

\section{References}

1. Reavley N, Cvetkovski S, Jorm AF, Lubman Dl: Help-seeking for substance use, anxiety and affective disorders among young people: results from the 2007 Australian National Survey of Mental Health and Wellbeing. Aust N Z J Psychiatry 2010, 44:729-735.

2. Hickie I, Groom G: Primary care-led mental health service reform: an outline of the Better Outcomes in Mental Health Care initiative. Australas Psychiatry 2002, 10:376-382.

3. Littlefield L, Giese J: The genesis, implementation and impact of the Better Access mental health initiative. Clin Psychol 2008, 12(2):42-49.

4. Bassilios B, Pirkis J, Fletcher J, Burgess P, Gurrin L, King K, Kohn F, Blashki G: The complementarity of two major Australian primary mental health care initiatives. Aust NZ J Psychiatry 2010, 44:997-1004.
5. Morley B, Pirkis J, Naccarella L, Kohn F, Blashki G, Burgess P: Improving access to and outcomes from mental health care in rural Australia. Aust J Rural Health 2007, 15:304-312.

6. Pirkis J, Bassilios B, Fletcher J, Sanderson K, Spittal MJ, King K, Kohn F, Burgess P, Blashki G: Clinical improvement after treatment provided through the Better Outcomes in Mental Health Care (BOiMHC) programme: Do some patients fare better than others? Aust N Z J Psychiatry 2011, 45:289-298.

7. Pirkis J, Stokes D, Morley B, Kohn F, Mathews R, Naccarella L, Blashki G, Shandley K, Littlefiled L, Burgess P: Impacts of Australia's Better Outcomes in Mental Health Care program for psychologists. Aust Psychol 2006, 41(3):152-159.

8. Rickwood DJ, Telford NR, Parker AG, Tanti CJ, McGorry PD: Headspace Australia's innovation in youth mental health: who are the clients and why are they presenting? Med J Aust 2014, 200:1-4.

9. Harris M, Pirkis J, Burgess P, Olesen S, Bassilios B, Fletcher J, Blashki G, Scott A: Evaluation of the Better Access to Psychiatrists, Psychologists and GPS through the Medicare Benefits Schedule initiative - Component B: An analysis of Medicare Benefits Schedule (MBS) and Pharmaceutical Benefits Scheme (PBS) administrative data. Melbourne: Melbourne School of Population Health, The University of Melbourne; 2010.

10. Bassilios B, Nicholas A, Reifels L, Machlin A, Ftanou M, King K, Fletcher J, Blashki G, Burgess P, Pirkis J: Evaluating the Access to Allied Psychological Services (ATAPS) program: Consolidated 10-year Report. Melbourne: Centre for Health Policy, Programs and Economics at the University of Melbourne; 2013.

11. Fenger M, Mortensen EL, Poulsen S, Lau M: No-shows, drop-outs and completers in psychotherapeutic treatment: Demographic and clinical predictors in a large sample of non-psychotic patients. Nord J Psychiatry 2011, 65:183-191.

12. Burgess P, Pirkis JE, Slade TN, Johnston AK, Meadows GN, Gunn JM: Service use for mental health problems: findings from the 2007 National Survey of Mental Health and Wellbeing. Aust N Z J Psychiatry 2009, 43:615-623.

13. Australian Bureau of Statistics: Australian demographic statistics, June 2012. Canberra: ABS; 2012:3101.0

14. Judd F, Komiti A, Jackson H: How does being female assist help-seeking for mental health problems? Aust NZ J Psychiatry 2008, 42(1):24-29.

15. Berger $\mathrm{LL}$, Addis ME, Green JD, Mackowiak C, Goldberg V: Men's reactions to mental health labels, forms of help-seeking, and sources of help-seeking advice. Psychol Men Masculinity 2013, 14(4):433-443.

16. Cotton SM, Wright A, Harris MG, Jorm AF, McGorry PD: Influence of gender on mental health literacy in young Australians. Aust N Z J Psychiatry 2006, 40:790-796.

17. Australian Bureau of Statistics (ABS): Population distribution, Aboriginal and Torres Strait Islander Australians. Canberra: Australian Bureau of Statistics; 2006.

18. Jorm AF, Bourchier SJ, Cvetkovski S, Stewart G: Mental health of Indigenous Australians: a review of findings from community surveys. Med J Aust 2012, 196(2):118-121.

19. Karmel R: Data linkage protocols using a statistical linkage key. Canberra: Australian Institute of Health and Welfare; 2005.

20. Australian Institute of Health and Welfare: Young Australians: their health and wellbeing 2011. Cat. no. PHE 140. Canberra: AlHW; 2011.

21. Australian Bureau of Statistics: National Survey of Mental Health and Wellbeing: Summary of Results. Canberra: Australian Bureau of Statistics; 2007.

\section{doi:10.1186/1752-4458-8-10}

Cite this article as: Bassilios et al:: Uptake of a national primary mental health program by young people in Australia. International Journal of Mental Health Systems 2014 8:10. 